\title{
Compound heterozygous LDLR variant in severely affected familial hypercholesterolemia patient
}

\author{
Faisal A. Al-Allaf1,2,3\# ${ }_{\varpi}$, Abdullah Alashwal ${ }^{4 \#}$, Zainularifeen Abduljaleel ${ }^{1,2}$, \\ Mohiuddin M. Taher 1,2 , Abdellatif Bouazzaoui ${ }^{1,2}$, Hala Abalkhail ${ }^{4}$, Ahmad F. Al-Allaf ${ }^{5}$ and \\ Mohammad Athar1,2\#凶
}

\begin{abstract}
'Department of Medical Genetics, Faculty of Medicine, Umm Al-Qura University, Makkah, Saudi Arabia; ${ }^{2}$ Science and Technology Unit, Umm Al-Qura University, Makkah, Saudi Arabia; ${ }^{3}$ Molecular Diagnostics Unit, Department of Laboratory and Blood Bank, King Abdullah Medical City, Makkah, Saudi Arabia; ${ }^{4 K i n g}$ Faisal Specialist Hospital and Research Centre, Riyadh, Saudi Arabia; ${ }^{5}$ Faculty of Medicine, Alfaisal University, Riyadh, Saudi Arabia
\end{abstract}

Familial hypercholesterolemia (FH) is most commonly caused by mutations in the LDL receptor (LDLR), which is responsible for hepatic clearance of $L D L$ from the blood circulation. We described a severely affected FH proband and their first-degree blood relatives; the proband was resistant to statin therapy and was managed on an LDL apheresis program. In order to find the causative genetic variant in this family, direct exon sequencing of the $L D L R, A P O B$ and PCSK9 genes was performed. We identified a compound heterozygous mutation in the proband with missense p.(W577C) and frameshift p.(G676Afs*33) variants at exons 12 and 14 of the LDLR gene respectively. DNA sequencing of LDLR gene from the parents demonstrated that the missense variant was inherited from the mother and frameshift variant was inherited from the father. The frameshift variant resulted in a stop signal 33 codons downstream of the deletion, which most likely led to a truncated protein that lacks important functional domains, including the trans-membrane domain and the cytoplasmic tail domain. The missense variant is also predicted to be likely pathogenic and affect EGF-precursor homology domain of the LDLR protein. The segregation pattern of the variants was consistent with the lipid profile, suggesting a more severe FH phenotype when the variants are in the compound heterozygous state. The finding of a compound heterozygous mutation causing severe FH phenotype is important for the genotype-phenotype correlation and also enlarges the spectrum of FH-causative LDLR variants in the Arab population, including the Saudi population.

Key words: familial hypercholesterolemia (FH), low-density lipoprotein receptor (LDLR), compound heterozygous, missense variant, frameshift variant, sequencing, Arab, coronary artery disease (CAD), cholesterol, genetics

Received: 05 March, 2016; revised: 23 June, 2016; accepted: 04 October, 2016; available on-line: 23 November, 2016

\footnotetext{
e-mail: fallaf@uqu.edu.sa (FAAl-A); athar80@gmail.com, mabedar@uqu.edu.sa (MA)

\#Authors contributed equally to the manuscript

Abbreviations: CAD, Coronary artery disease; $C H D$, Coronary heart diseases; FH, Familial hypercholesterolemia; LDLR, low-density lipoprotein receptor; APOB, apolipoprotein B; PCSK9, Pro-protein convertase subtilisin/kexin type 9; DNA, Deoxyribonucleic acid; LDL, low-density lipoprotein; LDL-C, low-density lipoprotein-cholesterol; $\mathrm{HDL}$, High-density lipoprotein; HDL-C, High-density-lipoproteincholesterol; TC, Total cholesterol; TG, Triglycerides; EDTA, Ethylenediaminetetraacetic acid; PCR, Polymerase chain reaction; EGF, Epidermal growth factor.
}

\section{INTRODUCTION}

Coronary heart diseases (CHD) inflict heavy economical and social cost on most populations including Saudis and contribute significantly to their morbidity and mortality rates. Familial hypercholesterolemia $(\mathrm{FH})$ is hereditary in an autosomal dominant manner and is a major risk factor for the development of CHD (Cuchel et al., 2014). If untreated, persistent hypercholesterolemia may produce tendon xanthomata (Achilles, extensor tendons of hands and feet), cutaneous planar, corneal arcus and premature cardiovascular disease (Al-Allaf et al., 2015). Because the disease is initially asymptomatic and painless, the majority of patients may not be aware of their illness until a severe myocardial infarction occurrs in the fourth or fifth decade of life due to instant atheroma, which often leads to sudden cardiac death or other severe cardiovascular events (Al-Allaf et al., 2010). FH is most commonly caused by mutations in the LDL receptor (LDLR), which is responsible for hepatic clearance of low-density lipoprotein (LDL) from the blood circulation. $\mathrm{FH}$ can also be caused by certain mutations in the apolipoprotein $\mathrm{B}(A P O B)$ gene, which encodes the ligand for LDLR (Yang et al., 2007). The pro-protein convertase subtilisin/kexin type 9 (PCSK9) gene was considered the third gene with pathogenic mutations accounting for some FH cases (Abifadel et al., 2003; Timms et al., 2004).

More than 1700 different variants of the LDLR gene were found to cause familial hypercholesterolemia (www. ucl.ac.uk/ldlr), making genetic screening very laborious. Mutations in the LDLR gene were divided into five classes based on biochemical and functional studies on LDLR variants; such that Class 1 mutations include null alleles that lack any LDLR protein product. Class $2 \mathrm{mu}-$ tations encode LDL receptor (LDLR) proteins that are abnormally transported from the endoplasmic reticulum to the Golgi apparatus. In Class 3 mutations, LDLR protein shows defective binding of the LDL ligand, and Class 4 mutation genes encode LDLR with distupted internalization/endocytosis of LDL. Class 5 mutations in the LDLR gene encode LDLR which displays defective recycling (Jeon et al., 2005).

To date there is no cure for $\mathrm{FH}$. The primary goal of clinical management in severely affected patients is to control hypercholesterolemia in order to decrease the risk of atherosclerosis and to prevent CHD. The most common cholesterol-lowering agents are statin and its derivatives. Treatment with non-statin cholesterol lower- 
ing agents, for example bile acid resin (Davidson et al., 1999), niacin (Berge \& Canner, 1991), fibrate (Rubins et al., 1999) or cholesterol absorption inhibitor (Sudhop et al., 2002), is also recommended for certain cases. Several therapeutic approaches were developed recently to lower LDL-C, either as monotherapy or in combination with statins (El Harchaoui et al., 2008) including: squalene synthase inhibitors, microsomal triglyceride transfer protein inhibitors (Cuchel et al., 2007), siRNA for PCSK9 (Frank-Kamenetsky et al., 2008) or for apolipoprotein B-100 (Soutschek et al., 2004) silencing, antisense PCSK9 (Gupta et al., 2010), and antisense apolipoprotein B-100 (Raal et al., 2010). However, even after treatment with a combination therapy, the majority of severely affected FH patients may still have extremely raised LDL-C serum levels (Gagne et al., 2002) and their risk of CHD remains unacceptably high. The preferred treatment for these patients is weekly or fortnightly plasma apheresis or LDL apheresis, a physical procedure in which LDL is selectively removed from the blood by running the plasma through columns that bind the LDL. LDL apheresis may lower LDL-C levels by about $55 \%$ and delay the onset and progression of atherosclerosis (Thompson et al., 2010; Al-Allaf et al., 2010).

In the majority of studied populations, the heterozygote form occurs in less than 1:500 and the homozygous form is one in a million (Heath et al., 2001; Soutar \& Naoumova, 2007). Some populations, such as Lebanese, French Canadians, Dutch Afrikaners and Ashkenazi Jews, are at a higher risk for $\mathrm{FH}$ due to the increased prevalence of heterozygous FH-associated mutations in the LDLR gene (Austin et al., 2004; Cuchel et al., 2014). However, recent studies in general populations suggested that the incidence of heterozygous FH based on the Dutch Lipid Clinic Network criteria may be as high as 1 in 200 (Nordestgaard et al., 2013) or, for molecularly defined heterozygous FH, 1 in 244 (Sjouke et al., 2015). Subsequently, homozygous FH may affect as many as 1 in 160000-300000 persons (Nordestgaard et al., 2013; Cuchel et al., 2014). The highest frequency of heterozygosity with the prevalence of less than 1:80 was found in the Afrikaner population in South Africa (Steyn et al., 1996). Studies on the French Canadian population where five common mutations were reported showed a frequency of 1:270 (Leitersdorf et al., 1990; Hobbs et al., 1992; Zetterstrom et al., 2011). This unusual high frequency is due to founder effects and consanguinity and no heterozygote advantage was identified. The prevalence of FH in Saudi Arabia is not known and there are limited reports on the molecular characteristics of FH. The disease may have a higher prevalence in Saudi Arabia than in other neighboring countries because of consanguineous marriages exceeding 50\% (Jaber et al., 1998); and due to the lack of national registries and genetic screening for $\mathrm{FH}$, the disease is underdiagnosed and underestimated.

Recently we reported two novel mutations in the LDLR gene causing FH in severely affected Saudi patients. The first was a novel nonsense (Al-Allaf et al., 2014) and the second was a novel frameshift variant (AlAllaf et al., 2015; Al-Allaf et al.,2016). In continuation to our further mutation screening for $\mathrm{FH}$ patients, herein, we describe a compound heterozygous mutation with missense and frameshift variants identified in the LDLR gene in severely affected FH patient who was resistant to statin therapy and was managed on an LDL apheresis program.

\section{MATERIALS AND METHODS}

Subjects. Recently we analyzed and reported two novel variants in the 23 subjects including 12 probands and 11 first-degree blood relatives from 12 unrelated Saudi families with FH (Al-Allaf et al., 2014; Al-Allaf et al., 2015; Al-Allaf et al., 2016). In this study the analysis was performed on five subjects including one proband and their four first-degree blood relatives of a family that originates from a tribe that lives in the Northern region of Saudi Arabia. The proband was clinically diagnosed with homozygous FH. The proband was resistant to statin therapy and was managed on an LDL apheresis program. The sample collection and study were performed

Table 1. Description and Lipid profile of the studied family with the missense and frameshift variants of the LDLR gene.

\begin{tabular}{|c|c|c|c|c|c|}
\hline Family members & Father & Mother & Proband & Brother & Sister \\
\hline $\begin{array}{l}\text { Missense variant in } \\
\text { LDLR exon } 12\end{array}$ & - & $\begin{array}{l}\text { c. } 1731 \mathrm{G}>\mathrm{T}, \\
\text { p.(W577C), Htz }\end{array}$ & $\begin{array}{l}\text { c.1731G>T, } \\
\text { p.(W577C), Htz }\end{array}$ & $\begin{array}{l}\text { c.1731G>T, } \\
\text { p.(W577C), Htz }\end{array}$ & - \\
\hline $\begin{array}{l}\text { Frameshift variant in } \\
\text { LDLR exon } 14\end{array}$ & $\begin{array}{l}\text { c.2027delG, } \\
\text { p.(G676Afs*33), Htz }\end{array}$ & - & $\begin{array}{l}\text { c.2027delG, } \\
\text { p.(G676Afs*33), Htz }\end{array}$ & - & - \\
\hline $\begin{array}{l}\text { Silent variant in } \\
\text { LDLR exon } 12\end{array}$ & - & $\begin{array}{l}\text { c. } 1725 \mathrm{C}>\mathrm{T}, \text { p. }(=), \\
\mathrm{Htz}\end{array}$ & $\begin{array}{l}\text { c. } 1725 \mathrm{C}>\mathrm{T}, \mathrm{p} .(=), \\
\mathrm{Htz}\end{array}$ & $\begin{array}{l}\text { c. } 1725 \mathrm{C}>\mathrm{T}, \mathrm{p} .(=), \\
\mathrm{Htz}\end{array}$ & $\begin{array}{l}\text { c. } 1725 \mathrm{C}>\mathrm{T}, \text { p. }(=), \\
\text { Htz }\end{array}$ \\
\hline $\operatorname{Sex}(M / F)$ & $M$ & $\mathrm{~F}$ & $M$ & $M$ & $\mathrm{~F}$ \\
\hline Age (Year) & 41 & 38 & 6 & 13 & 9 \\
\hline $\begin{array}{l}\text { Total Cholesterol } \\
(\mathrm{mmol} / \mathrm{l})\end{array}$ & 11.3 & 7.6 & 21.3 & 7.4 & 4.6 \\
\hline $\begin{array}{l}\text { Triglyceride } \\
(\mathrm{mmol} / \mathrm{l})\end{array}$ & 3.1 & 1.3 & 2.5 & 1.2 & 0.6 \\
\hline $\begin{array}{l}\text { LDL-C } \\
(\mathrm{mmol} / \mathrm{l})\end{array}$ & 8.8 & 5.5 & 18 & 5.9 & 3 \\
\hline $\begin{array}{l}\mathrm{HDL}-\mathrm{C} \\
(\mathrm{mmol} / \mathrm{I})\end{array}$ & 0.93 & 1.39 & 0.87 & 0.98 & 1.37 \\
\hline Symptoms & No & No & $\begin{array}{l}\text { Tendon xanthomas, } \\
\text { corneal arcus }\end{array}$ & No & No \\
\hline Family history of CAD & Yes & Yes & Yes & Yes & Yes \\
\hline
\end{tabular}

Lipid profile represented here are untreated values. Normal range for lipid profile was described in our recent publication (Al-Allaf et al., 2014). Abbreviations: M, male; F, female; HDL-C, high-density lipoprotein-cholesterol; LDL-C, low-density lipoprotein-cholesterol; LDLR, low-density lipoprotein receptor; CAD, coronary artery disease. 
in accordance with the Research Ethics Committees regulations at King Faisal Specialist Hospital and Research Center (KFSHRC), Riyadh, Saudi Arabia and all subjects gave informed consent. The enrollment criteria for the patients' genetic screening were based on Simon Broome register (Scientific Steering Committee, 1991).

DNA sequencing. Genomic DNA was isolated from EDTA-treated whole blood using the MagNA Pure Compact Nucleic Acid Isolation Kit I (Roche, Basel, Switzerland) according to the manufacturer's instructions. Polymerase chain reaction (PCR) amplification of the LDLR gene (including the 18 coding exons and flanking intron regions), $A P O B$ gene (exon 26 of the $A P O B$ gene containing codons 3475-3592, which harbors three known pathogenic variant sites, R3500Q, R3500W and R3527Q) and PCSK9 gene (the 12 exons and flanking intron regions) was performed. Description of the primers used for amplifying and sequencing fragments was provided in Supplementary Table 1 (at www.actabp.pl). PCR was performed with $100 \mathrm{ng}$ genomic DNA using the HotStarTaq Plus DNA Polymerase Kit (Qiagen, Hilden, Germany) as follows: Taq polymerase was activated at $94^{\circ} \mathrm{C}$ for $5 \mathrm{~min}$, followed by 35 cycles of denaturing at $94^{\circ} \mathrm{C}$ for $30 \mathrm{~s}$, annealing at $61-64^{\circ} \mathrm{C}$ for $30 \mathrm{~s}$, extension at $72^{\circ} \mathrm{C}$ for $45 \mathrm{~s}$, and final extension at $72^{\circ} \mathrm{C}$ for $5 \mathrm{~min}$. The amplified products were also separated on agarose gel to ensure the proper size and quality of the band (representative gel images are shown in Supplemental Material; Appendix B at www.actbp.pl). The PCR products were purified with magnetic beads method using Agencourt AMPure XP kit (Beckman Coulter, Brea, CA, USA). The purified products were used as templates for direct sequencing with a BigDye Terminator v3.1 cycle sequencing ready reaction kit (Applied Biosystems, Foster City, CA, USA). The sequencing reaction products were purified with BigDye X-terminator purification kit (Applied Biosystems) followed by capillary electrophoresis in an ABI 3500 Genetic analyzer (Applied Biosystems). The final analysis was performed using the Sequence Analysis Software v5.4 (Applied Biosystems). The LDLR transcript used for coding and protein position was NM_000527.The nomenclature of the identified variants was described as per the Mutalyzer program.

\section{RESULTS}

Two heterozygous variants c.1731G $>$ T, p.(W577C) and c.2027delG, p.(G676Afs*33) were found in exons 12 and 14 of the LDLR gene respectively in a proband of a Saudi family from a tribe which lives in the Northern region of Saudi Arabia. The pedigree structure of the family is shown in Fig. 1. Both variants were identified

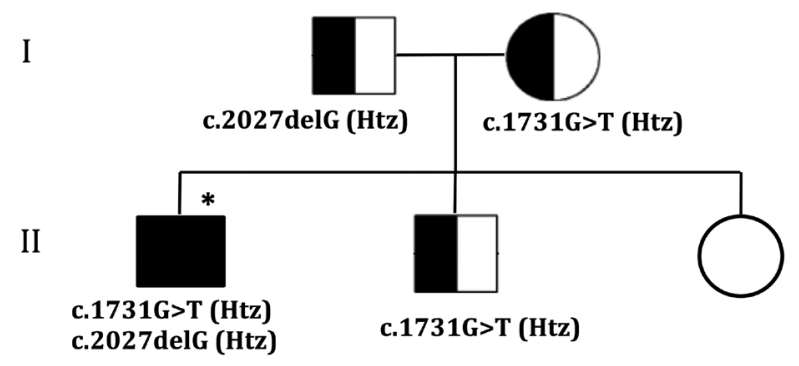

Figure 1. Pedigree of the patient family.

Filled symbols indicate compound heterozygous, half filled indicate heterozygous $(\mathrm{Htz})$ and unfilled indicate unaffected individuals. *Proband in proband, while his father carried one heterozygous variant (c.2027delG) and mother carried another heterozygous variant (c.1731G $>\mathrm{T}$ ). The brother of proband was found to be carrying one heterozygous (c.1731G $>$ T) variant. However, the sibling (sister) did not show any mutation in any of the three candidate ( $L D L R, A P O B$ and PCSK9) genes. In addition to this compound heterozygous variants, one known silent variant c. $1725 \mathrm{C}>\mathrm{T}$, p.(=), rs1799898, NM_001195798.1 was also identified in exon 12 of the LDLR gene (Table 1). There were no variants detected at exons 12 and 14 of the LDLR gene in 10 healthy individuals studied. Figure 2 shows results of the DNA sequence analysis of exon 12 and 14 of the LDLR gene. The lipid profile of all the studied subjects is presented in the Table 1 . The total and LDL cholesterol levels with values reaching 21.3 and $18.0 \mathrm{mmol} / 1$ respectively in proband are considered very high compared with the optimal level, which is $<2.59 \mathrm{mmol} / 1$ (LDL cholesterol). In addition to the high levels of lipid cholesterol, the proband also displayed tendon xanthoma and corneal arcus, was resistant to statin therapy and managed on an LDL apheresis program. There was CAD history present in the family (Table 1). This confirmed the loss of LDLR function as a result of compound heterozygous variant presence in the DNA sequence. Compound heterozygous missense and frameshift variants may be associated with the severity of the disease.

\section{DISCUSSION}

Familial hypercholesterolemia $(\mathrm{FH})$ is a lipid metabolism disorder that is genetically inherited in an autosomal dominant manner, which clinically results in high concentrations of plasma cholesterol bound to LDL. Ap-

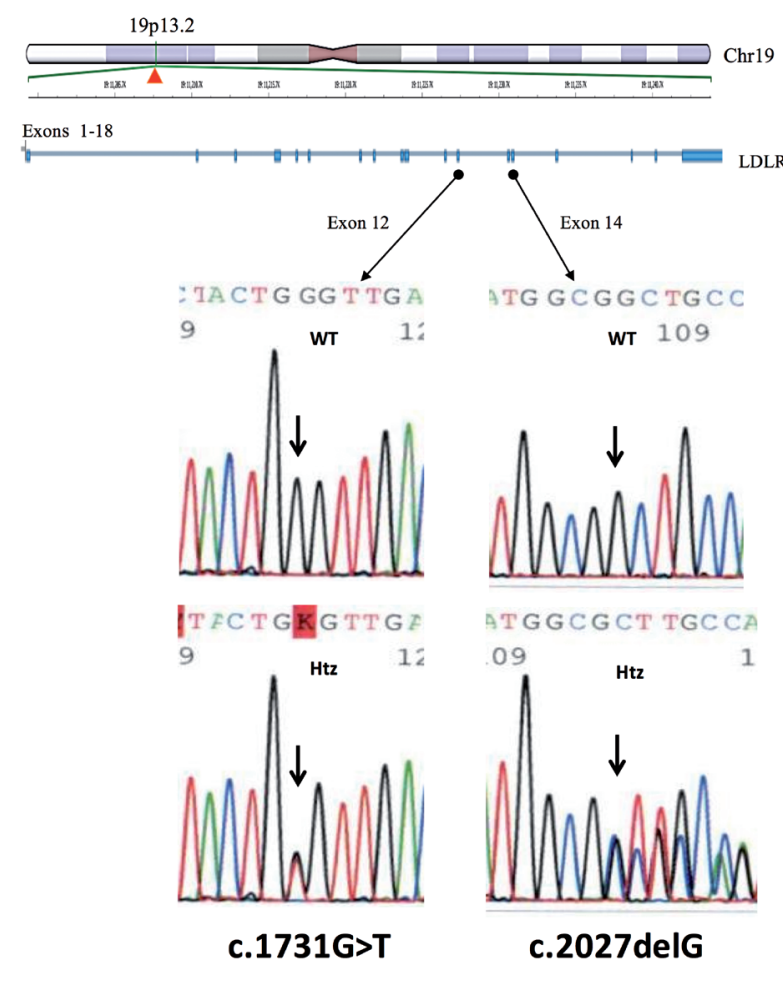

Figure 2. Structure and location of the LDLR gene on chromosome 19p13.2.

The position of the two variants, c.1731G >T and c.2027delG is indicated in exons 12 and 14 , respectively. Representative DNA sequence from the control individuals (Wild type; WT) and heterozygous $(\mathrm{Htz})$ of the family. 
proximately, half of the heterozygous men with familial hypercholesterolemia, if untreated, develops clinically evident CHD by the age of 55 years. Affected heterozygous women from the same families typically develop CHD about 9 years later than their affected male relatives (Lindgren et al. 1985). Therefore, our aim was to describe a compound heterozygous variant with known missense and frameshift variants identified in the LDLR gene in severely affected FH patient who was resistant to statin therapy and was managed on LDL apheresis program.

The segregation pattern of the variant was compatible with the lipid profile (Fig. 1, Table 1). The severity of $\mathrm{FH}$ was higher in compound heterozygous proband (Table 1), due to the missense variant at maternal allele and frameshift variant at paternal allele that is predicted to cause abnormal LDLR function; regular heterozygous individuals on the other hand showed a reduced level of FH phenotype as the presence of one normal allele provides residual LDLR protein function. It was reported that patients homozygous or compound heterozygous for LDLR mutations or double heterozygous for LDLR and $A P O B$ mutations have higher LDL-C levels, more extensive xanthomatosis and more severe premature CAD than simple heterozygotes for mutations in either of these genes or for missense mutations in PCSK9 gene (Muiya et al., 2009). To the best of our knowledge this is the first report of such a mutation in the LDLR gene in the Arab population, including the Saudi population.

Approximately $54 \%$ of all LDLR gene mutations that result in FH occur in the EGF-precursor homology domain (Al-Allaf et al., 2016), which means that this domain plays an important role in the function of the LDLR. The EGF-precursor homology domain controls lipoprotein release in low $\mathrm{pH}$ environments and the recycling of the receptor back to the cell surface ( $\mathrm{Ru}-$ denko \& Deisenhofer, 2003). The missense p.(W577C) and frameshift p.(G676Afs*33) variants reported here are also located in the EGF-precursor homology domain of the LDLR protein. Hattori et al (2002) described the missense variant p.(W577C) as predicted to be likely pathogenic and affect EGF-precursor homology domain of the LDLR protein. The LDLR protein and LDL uptake were each decreased to $64 \%$ of controls by this variant (Hattori et al., 2002).

Interestingly, the deletion mutation reported here, encodes a stop signal 33 codons downstream of the deletion, which could probably lead to either mRNA degradation or a truncated protein that lacks important functional domains. Furthermore, this truncated protein may be degraded and affect LDLR protein levels in mutation carriers; however, in case when a truncated protein survives in the cell, it could interfere with the normal assembly of the receptor protein complex. Similarly, we reported a novel nonsense variant in severely affected FH patients from a Saudi family who were also resistant to statin therapy and were managed on an LDL apheresis program (Al-Allaf et al., 2014). Furthermore, more recently, we also reported the novel frameshift mutation p.(G676Afs*33) as a highly recurrent mutation in LDLR gene observed among individuals belonging to a selected group of Saudi children who were also subjected to the LDL apheresis program (Al-Allaf et al., 2015; 2016).

In conclusion, the segregation pattern of the variants is consistent with the lipid profile, suggesting a more severe FH phenotype when the variants are in the compound heterozygous state. The finding of this study could be useful in developing critical genetic screening for severely affected FH patients. These results also en- large the spectrum of FH-causative LDLR mutations in the Arab population, including the Saudi population.

\section{Acknowledgements}

We are indebted to the subjects of this study and their family members for their cooperation. The authors would like to thank the Science and Technology Unit at Umm Al-Qura University for the continuous support. This work was supported by the National Science, Technology, and Innovative Plan (MAARIFAH) of the Kingdom of Saudi Arabia to Dr. Faisal A. Al-Allaf, (Grant Code: 08-BIO34-10).

\section{REFERENCES}

Abifadel M, Varret M, Rabès JP, Allard D, Ouguerram K, Devillers M, Cruaud C, Benjannet S, Wickham L, Erlich D, Derré A, Villéger L, Farnier M, Beucler I, Bruckert E, Chambaz J, Chanu B, Lecerf JM, Luc G, Moulin P, Weissenbach J, Prat A, Krempf M, Junien C, Seidah NG, Boileau C (2003) Mutations in PCSK9 cause autosomal dominant hypercholesterolemia. Nat Genet 34: 154-156. doi: 10.1038/ng1161

Al-Allaf FA, Alashwal A, Abduljaleel Z, Taher MM, Siddiqui SS, Bouazzaoui A, Abalkhail H, Aun R, Al-Allaf AF, AbuMansour I, Azhar Z, Ba-hammam FA, Khan W, Athar M (2016) Identification of a recurrent frameshift mutation at the LDLR exon 14 (c.2027delG, p.(G676Afs*33)) causing familial hypercholesterolemia in Saudi Arab homozygous children. Genomics 107: 24-32. doi:10.1016/j.ygeno.2015.12.001

Al-Allaf FA, Athar M, Abduljaleel Z, Taher MM, Khan W, Ba-Hammam FA, Abalkhail H, Alashwal A (2015) Next generation sequencing to identify novel genetic variants causative of autosomal dominant familial hypercholesterolemia associated with increased risk of coronary heart disease. Gene 565: 76-84. doi: 10.1016/j. gene.2015.03.064

Al-Allaf FA, Athar M, Abduljaleel Z, Bouazzaoui A, Taher MM, Own R, Al-Allaf AF, AbuMansour I, Azhar Z, Ba-hammam FA, Abalkhail H \& Alashwal A (2014) Identification of a novel nonsense variant c.1332dup, p.(D445*) in the LDLR gene that causes familial hypercholesterolemia. Human Genome Variation 1: 14021. doi:10.1038/hgv.2014.21

Al-Allaf FA, Coutelle C, Waddington SN, David AL, Harbottle R, Themis M (2010) LDLR-Gene therapy for familial hypercholesterolaemia: problems, progress, and perspectives. Int Arch Med 3: 36. doi: 10.1186/1755-7682-3-36

Austin MA, Hutter CM, Zimmern RL, Humphries SE (2004) Familial hypercholesterolemia and coronary heart disease: a HuGE association review. Am I Epidemiol 160: 421-429. doi: 10.1093/aje/kwh237

Berge KG, Canner PL (1991) Coronary drug project: experience with niacin. Coronary Drug Project Research Group. Eur J Clin Pharmacol 40: S49-S51

Cuchel M, Bruckert E, Ginsberg HN, Raal FJ, Santos RD, Hegele RA, Kuivenhoven JA, Nordestgaard BG, Descamps OS, SteinhagenThiessen E, Tybjærg-Hansen A, Watts GF, Averna M, Boileau C, Bore'n J, Catapano AL, Defesche JC, Hovingh GK, Humphries SE, Kovanen PT, Masana L, Pajukanta P, Parhofer KG, Ray KK, Stalenhoef AFH, Stroes E, Taskinen MR, Wiegman A, Wiklund O, Chapman MJ, European Atherosclerosis Society Consensus Panel on Familial Hypercholesterolaemia (2014) Homozygous familial hypercholesterolaemia: new insights and guidance for clinicians to improve detection and clinical management. A position paper from the Consensus Panel on Familial Hypercholesterolaemia of the European Atherosclerosis Society. Eur Heart J 35: 2146-2157. doi: 10.1093/eurheartj/ehu274

Cuchel M, Bloedon LT, Szapary PO, Kolansky DM, Wolfe ML, Sarkis A, Millar JS, Ikewaki K, Siegelman ES, Gregg RE, Rader DJ (2007) Inhibition of microsomal triglyceride transfer protein in familial hypercholesterolemia. N Engl J Med 356: 148-156. doi: 10.1056/NEJMoa061189

Davidson MH, Dillon MA, Gordon B, Jones P, Samuels J, Weiss S, Isaacsohn J, Toth P, Burke SK (1999) Colesevelam hydrochloride (cholestagel): a new, potent bile acid sequestrant associated with a low incidence of gastrointestinal side effects. Arch Intern Med 159: 1893-1900

El Harchaoui K, Akdim F, Stroes ES, Trip MD, Kastelein JJ (2008) Current and future pharmacologic options for the management of patients unable to achieve low-density lipoprotein-cholesterol goals with statins. Am J Cardiovasc Drugs 8: 233-242

Frank-Kamenetsky M, Grefhorst A, Anderson NN, Racie TS, Bramlage B, Akinc A, Butler D, Charisse K, Dorkin R, Fan Y, Gamba-Vitalo C, Hadwiger P, Jayaraman M, John M, Jayaprakash KN, 
Maier M, Nechev L, Rajeev KG, Read T, Rohl I, Soutschek J, Tan P, Wong J, Wang G, Zimmermann T, de Fougerolles A, Vornlocher HP, Langer R, Anderson DG, Manoharan M et al (2008) Therapeutic RNAi targeting PCSK9 acutely lowers plasma cholesterol in rodents and LDL cholesterol in nonhuman primates. Proc Natl Acad Sci U S A 105: 11915-11920. doi: 10.1073/pnas.0805434105

Gagne C, Gaudet D, Bruckert E (2002) Efficacy and safety of ezetimibe coadministered with atorvastatin or simvastatin in patients with homozygous familial hypercholesterolemia. Circulation 105: 2469-2475. doi: 10.1161/01.CIR.0000018744.58460.62

Gupta N, Fisker N, Asselin MC, Lindholm M, Rosenbohm C, Orum H, Elmen J, Seidah NG, Straarup EM (2010) A locked nucleic acid antisense oligonucleotide (LNA) silences PCSK9 and enhances LDLR expression in vitro and in vivo. PLOS One 5: e10682. doi: 10.1371/journal.pone.0010682

Heath KE, Humphries SE, Middleton-Price H, Boxer M (2001) A molecular genetic service for diagnosing individuals with familial hypercholesterolaemia $(\mathrm{FH})$ in the United Kingdom. Eur J Hum Genet 9: 244-252. doi: $10.1038 /$ s.ejhg. 5200633

Hattori H, Hirayama T, Nobe Y, Nagano M, Kujiraoka T, Jun Ishii TE, Tsuji M, Emi M (2002) Eight novel mutations and functional impairments of the LDL receptor in familial hypercholesterolemia in the north of Japan. J Hum Genet 47: 80-87

Hobbs HH, Brown MS, Goldstein JL (1992) Molecular genetics of the LDL receptor gene in familial hypercholesterolemia. Hum Mutat 1 : 445-466. doi: 10.1002/humu.1380010602

Jaber L, Halpern GJ \& Shohat M (1998) The impact of consanguinity worldwide. Community Genet 1: 12-17

Jeon H and Blacklow SC (2005) Structure and physiologic function of the low-density lipoprotein receptor. Anmu Rev Biochem 74: 535-562. doi: 10.1146/annurev.biochem.74.082803.133354

Leitersdorf E, Tobin EJ, Davignon J and Hobbs HH (1990) Common low-density lipoprotein receptor mutations in the French Canadian population. J Clin Invest 85: 1014-1023. doi: 10.1172/JCI114531

Lindgren V, Luskey KL, Russell DW \& Francke U (1985) Human genes involved in cholesterol metabolism: chromosomal mapping of the loci for the low density lipoprotein receptor and 3-hydroxy3-methylglutaryl-coenzyme A reductase with cDNA probes.Proc Natl Acad Sci U S A 82: 8567-8571

Nordestgaard BG, Chapman MJ, Humphries SE, Ginsberg HN, Masana L, Descamps OS, Wiklund O, Hegele RA, Raal FJ, Defesche JC, Wiegman A, Santos RD, Watts GF, Parhofer KG, Hovingh GK, Kovanen PT, Boileau C, Averna M, Borén J, Bruckert E, Catapano AL, Kuivenhoven JA, Pajukanta P, Ray K, Stalenhoef AF, Stroes E, Taskinen MR, Tybjærg-Hansen A, Panel EASC (2013) Familial hypercholesterolaemia is underdiagnosed and undertreated in the general population: guidance for clinicians to prevent coronary heart disease: consensus statement of the European Atherosclerosis Society. Eur Heart J 34: 3478-3490. doi: 10.1093/eurhearti/eht273

Muiya P, Wakil S, Al-Najai M, Meyer BF, Al-Mohanna F, Alshahid M, Dzimiri N (2009) Identification of loci conferring risk for premature CAD and heterozygous familial hyperlipidemia in the LDLR, APOB and PCSK9 genes. Int. J. Diabetes Mellit 1: 16-21

Rudenko G, Deisenhofer J (2003) The low-density lipoprotein receptor: ligands, debates and lore. Curr Opin Struct Biol 13: 683-689

Raal FJ, Santos RD, Blom DJ, Marais AD, Charng MJ, Cromwell WC, Lachmann RH, Gaudet D, Tan JL, Chasan-Taber S, Tribble DL, Flaim JD, Crooke ST (2010) Mipomersen, an apolipoprotein
B synthesis inhibitor, for lowering of LDL cholesterol concentrations in patients with homozygous familial hypercholesterolaemia: a randomised, double-blind, placebo-controlled trial. Lancet 375: 9981006. doi: 10.1016/S0140-6736(10)60284-X

Rubins HB, Robins SJ, Collins D, Fye CL, Anderson JW, Elam MB, Faas FH, Linares E, Schaefer EJ, Schectman G, Wilt TJ, Wittes J (1999) Gemfibrozil for the secondary prevention of coronary heart disease in men with low levels of high-density lipoprotein cholesterol. Veterans Affairs High-Density Lipoprotein Cholesterol Intervention Trial Study Group. N Engl J Med 341: 410-418. doi: 10.1056/ NEJM199908053410604

Scientific Steering Committee on behalf of the Simon Broome Register Group (1991) Risk of fatal coronary heart disease in familial hypercholesterolaemia. Bmj 303: 893-896

Sjouke B, Kusters DM, Kindt I, Besseling J, Defesche J, Sijbrands EJG, Roeters van Lennep JE, Stalenhoef AFH, Wiegman A, de Graaf J, Fouchier SW, Kastelein JJP, Hovingh GK (2015) Homozygous autosomal dominant hypercholesterolemia in the Netherlands: prevalence, genotype-phenotype relationship and clinical outcome. Eur Heart J 36: 560-565. doi: 10.1093/eurheartj/ehu058

Soutar AK, Naoumova RP (2007) Mechanisms of disease: genetic causes of familial hypercholesterolemia. Nat Clin Pract Cardiovasc Med 4: 214-225. doi: 10.1038/ncpcardio0836

Soutschek J, Akinc A, Bramlage B, Charisse K, Constien R, Donoghue M, Elbashir S, Geick A, Hadwiger P, Harborth J, John M, Kesavan V, Lavine G, Pandey RK, Racie T, Rajeev KG, Rohl I, Toudjarska I, Wang G, Wuschko S, Bumcrot D, Koteliansky V, Limmer S, Manoharan M, Vornlocher HP (2004) Therapeutic silencing of an endogenous gene by systemic administration of modified siRNAs. Nature 432: 173-178. doi:10.1038/nature03121

Steyn K, Goldberg YP, Kotze MJ, Steyn M, Swanepoel AS, Fourie JM, Coetzee GA, Van der Westhuyzen DR (1996) Estimation of the prevalence of familial hypercholesterolaemia in a rural Afrikaner community by direct screening for three Afrikaner founder low density lipoprotein receptor gene mutations. Hum Genet 98: 479-484

Sudhop T, Lutjohann D, Kodal A, Igel M, Tribble DL, Shah S, Perevozskaya I, von Bergmann K (2002) Inhibition of intestinal cholesterol absorption by ezetimibe in humans. Circulation 106: 1943-1948. doi: 10.1161/01.CIR.0000034044.95911.DC

Thompson GR, Barbir M, Davies D, Dobral P, Gesinde M, Livingston M, Mandry P, Marais AD, Matthews S, Neuwirth C, Pottle A, le Roux C, Scullard D, Tyler C, Watkins S (2010) Efficacy criteria and cholesterol targets for LDL apheresis. Atherosclerosis 208: 317-321. doi: 10.1016/j.atherosclerosis.2009.06.010

Timms KM, Wagner S, Samuels ME, Forbey K, Goldfine H, Jammulapati S, Skolnick MH, Hopkins PN, Hunt SC, Shattuck DM (2004) A mutation in PCSK9 causing autosomal-dominant hypercholesterolemia in a Utah pedigree. Hum Genet 114: 349-353. doi: 10.1007/ s00439-003-1071-9

Yang KC, Su YN, Shew JY, Yang KY, Tseng WK, Wu CC and Lee YT (2007) LDLR and ApoB are major genetic causes of autosomal dominant hypercholesterolemia in a Taiwanese population. J Formos Med Assoc 106: 799-807. doi: 10.1016/S0929-6646(08)60044-3

Zetterström R (2011) Investigations on a child with familial hypercholesterolaemia. Acta Paediatr 100: 311-313. doi: 10.1111/j.16512227.2010.02020.x 